\title{
A study of the impact and effectiveness of scent used for promotion of products and services with low olfactory affinity
}

\author{
Jun Kumamoto \\ Tokai University, Tokyo, Japan \\ Adi Prasetyo Tedjakusuma \\ University of Surabaya, Surabaya, Indonesia
}

\begin{abstract}
The paper objective is to analyze the impact of two studies on scent marketing and discuss the feasibility of scent as an effective promotional tool for business. The first study surveyed 45 undergraduate students in writing at three-time periods, and the second study orally surveyed shoppers using an Automated Teller Machine (ATM) adjusted to emit scent. Our research undertook the uniquely challenging measurement of the effectiveness of scent marketing when applied to products and services that have low olfactory affinity. Findings from Study 1 revealed that 17\% (after 6 weeks) and 6\% (after 12 weeks) of participants accurately recognized a past-administered scent. Study 2 showed that $15 \%$ of the interviewees detected the scent flow around the machine at the time of exposure. This concludes that scent, can foster customers to create positive attitudes and positively impact purchase intention toward products and services even in the absence of scent affinity.
\end{abstract}

Keywords: scent marketing, olfactory affinity, purchase intention

\section{INTRODUCTION}

The first author has constructed an original classification for scent marketing applications utilizing two variables: 1) scent as one of the product attributes, and 2 ) the level of affinity of products to scent. The developed classification is illustrated in Table 1.

Table 1. Classification of scent marketing efforts

\begin{tabular}{lcc} 
& High affinity & Low affinity \\
\hline Basic attributes & A & C \\
Fringe attributes & B & D \\
\hline
\end{tabular}

Kumamoto (2013),p.71

We propose that the marketing approach for products and services corresponding to the D quadrant, where scent is a fringe attribute and the level of affinity is low, requires more focused efforts. Olfactory marketing for $\mathrm{D}$ dimension products and services should aim to expand consumer perceptions and accelerate competitor differentiation by utilizing scent as a new promotional scheme.

Compared to other quadrants, effective real-world applications within the $\mathrm{D}$ dimension are more demanding and challenging. Despite technological breakthroughs in the areas of informatics, material engineering, and human sensory responses, there are still many unexamined aspects of scent functionality which interplay across diverse fields such as biolo- gy, neurology, and psychology.

The objective of this paper is to assess findings gleaned from two studies on scent marketing and discuss the feasibility of scent as an effective marketing tool for products and services with a low olfactory affinity. A multi-method approach was utilized. Study 1 consisted of a written longitudinal survey of undergraduate students and focused on scent recall over time. Study 2 consisted of an oral survey of Tokyo shoppers at a scent-emitting ATM, and assessed how consumers notice scent and respond generally to scent marketing.

The real-world problems and prospects of scent marketing are discussed in the paper's conclusion.

\section{LITERATURE REVIEW}

According to Vlahos (2007) scent marketing refers to the usage of scents to set a mood, promote products or position a brand. The main goal of scent marketing is the creation of a pleasant atmosphere in order to encourage customers to remain in stores longer to accordingly buy more products or raise consumption (Michell et al. 1995 \& Hirt 2009). It relies on the neuropsychological processing of olfacto- 
ry stimuli in the human brain (Emsenhuber 2009). Meanwhile, 'olfaction' is described as the sense of smell, regarded as the most emotional of the five senses and also considered to be the most difficult sense to study, due to its high variability in the affective responses related to scents (Hudson \& Distel 2002).

The market for scent or aroma-related business has been expanding in Japan. According to the Japan Aroma Environment Association, the aroma business market in 2011 was estimated at 265.4 billion yen, of which 201.7 billion yen were generated from cosmetics and fabric softeners using essences. The latter market continues to rapidly expand.

According to the Nikkei Marketing Journal, an increasing numbers of consumers are looking for different scents to enjoy when using fabric softeners. Japanese consumers who were content with accumulating financial wealth in the 1980s and 1990s tended to pursuit a simple lifestyle, which promoted the use of non-scented goods. This period also led to peaked interest in natural aromas (Kumamoto 2013). In the 2000s, the Japanese citizenry started to enjoy different aromas in order to express identity and personality. Their needs coincided perfectly with the introduction of heavily-scented fabric softener brands from the U.S. into the Japanese market. After of witnessing the success of U.S. products, Japanese manufacturers such as Kao Corporation and Lion Corporation responded by launching several softeners brands mirroring the same value to users. The current scented softener market has been saturated with many brands offering diverse usages due to users' diversified and individualized needs.

The Japanese Patent Agency has announced the addition of "sound", "movement", "hologram", "color" and "position" as new types of protected marks in the amendment of Japanese trademark law. Due to this action, companies are now able to promote their products and services with novel schemes to penetrate new markets, enhance brand power, and benefit from greater legal protection and product recognition. Scent, however, was not included among the newly protected types of marks. Scent tends to alter its character chronologically. It is also difficult to define the legal scope of trademark rights because consumers recall olfactory-associated objectives differently. Acknowledging the lack of trademark protection, if customers recall a particular brand or product when they are exposed to a particular aroma, this scent could be associated with the company's mark and thus serve as a powerful tool for brand identification and originality.

This paper supports the validity of scent as a promotional tool for improving consumer perceptions of particular brands. Two types of surveys are conducted. Study 1 assesses scent recall among undergraduate students using a written longitudinal survey. Study 2 assesses consumer responses to scenting the context of ATM usage by means of an oral survey.

\section{STUDY 1: SCENT RECALL}

\subsection{Purpose}

The purpose of this study was to measure the amount and type of aromatic information examinees recall after certain periods of time. Data was sought to assess the effectiveness of scent promotional activities as a clue to "brand (or store, service) recall".

\subsection{Method}

Forty-five (45) undergraduate student participants in the first author's marketing class were surveyed in writing on three occasions for this study (tests $X, Y$ and $Z$ ). To begin, commercially obtained stickers that emitted orange scent when rubbed were affixed to printed copies of the course syllabus and distributed to all the students. Immediately thereafter, the students were instructed to rub and smell the stickers (test $X$ ).

Students were then asked to write down answers to the following open-ended questions: XQ1) please state your image or impression of the scent, XQ2) do you like or dislike the scent? And XQ3) what do you recall or associate with the scent? After 6 weeks, the same orange-scent was affixed onto the top of the students' mid-term exam question sheets distributed to students (test $Y$ ). Apart from the exam related questions, an additional question was added which inquired, "Is there anything you have noticed when you received the question sheet?" Answers were recorded in an open-ended format.

Figure 1. Picture of the sticker. A picture of the printed syllabus was taken by the first author.

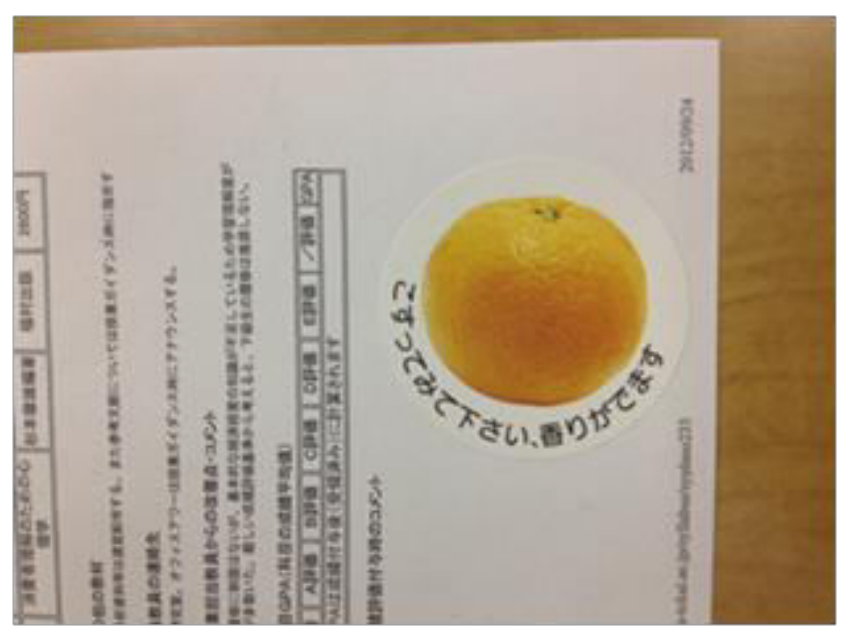


After 12 weeks from the original syllabus distribution, another exam question sheet with the same orange-scent identically affixed thereto was distributed to students (test $Z$ ), with the same added question and open-ended response format used in (test Y).

\subsection{Result}

Demographic profile of the 45 undergraduate participants: $71 \%$ male and $29 \%$ female. The largest portions of them were juniors $(56 \%)$, followed by sophomores $(35 \%)$.

\subsubsection{Test $X$}

The following text answers were collected in XQ1: Dry, clear, refreshing smell; Good orange smell; Sweet orange, something relaxing; Image of countryside, farmland; Summer, morning, showering; Chewing gums, orange candy; and Toilet diffuser at expensive restaurant. As for XQ2, all participants provided affirmative feedback (Yes $=100 \%$ ). For XQ3, there were various answers collected. 24\% answered natural scent items such as "orange", "tangerine", and "hand smell after peeling oranges". On the other hand, $27 \%$ of them named artificial scented products such as "laundry detergent", "car air freshener", "shampoo for kids", and "deodorant". Others included "drinks, foods, confectionaries, medicines (19\%)", "stationeries, aroma products (14\%)", and "events, seasonal expressions (16\%)". The results of this test indicated that association of scent provided were extremely broad and were driven from individualized experiences and memories in the past.

\subsubsection{Test $Y$}

The authors measured the accurate scent recall of participants if they answered, "the same orange aroma of the stickers on the syllabus". As a result, 17\% of participants accurately recalled the original sticker's orange scent. $61 \%$ answered "orange, citruslike smell" and $14 \%$ provided answers referencing some sort of smell on the paper. $8 \%$ answered things irrelevant to scent (text font size, layout of the title, etc.), which were not modified at all

\subsubsection{Test $Z$}

As the authors had predicted, a smaller percentage of participants $(6 \%)$ accurately recalled the original scent after 12 weeks. However, a large percentage of them continued to recognize an, "orange, citruslike smell" (67\%). The percentage of participants that did not answer anything relevant to scent was $21 \%$.
It can be inferred from our findings that a significant segment of the population is quite sensitive to olfactory information. The results also suggest that remembrance of olfactory information dissipates chronologically. However, correlation analysis did not support the expected link between scent association (XQ3) and scent recall (test $Y$ and $Z$ ) [for test $Y$ $\left(X^{2}=0.23\right)$ and test $\left.Z\left(X^{2}=0.257\right)\right]$.

\section{STUDY 2: RECOGNITION OF SCENT}

\subsection{Purpose}

The aim of this oral survey was to i) measure the influence of scent on consumer recognition of a product, and ii) evaluate consumer response to the usage of scent with low affinity products. It was hypothesized that; H1) the perception of a product's brand could be improved with scent, and also that, H2) a scented environment for consumers would increase consumption

\subsection{Method}

With the cooperation of a Japanese ATM company, 69 shoppers were orally surveyed in person at a retail outlet in Tokyo. The "orange sweet" aroma was selected as a scent and emitted around the ATM machine with custom-made micro diffusers. Those diffusers were attached to the partition panel aside the machine. The interviewers were standing near the panel.

\subsection{Result}

$71 \%$ of interviewees were between 30 to 50 years old (self-reported). $68 \%$ of them were female homemakers and $25 \%$ were business persons.

It emerged that the majority of interviewees had prior knowledge of the ATM's existence, and there were few participants who responded that they had, "noticed it [ATM] due to the scent". Other answers such as "billboards", "word-of-mouths", "asked to store staffs" were likewise seldom recorded. Hence, H1 was not been supported by the results of study 2 .

The survey questions relating to $\mathrm{H} 2$, however, provided some positive feedback regarding scent. Among the interviewees, $15 \%$ detected the scent emitted around the machine. Many of those who did not detect the scent were wearing a mask (interviews were conducted in January). Others responded that they could only smell of bread and butter, which can be attributed to the ATM's proximity to a retail bakery shop. 
Interviewers requested all of the interviewees to approach the ATM and inquired as to their impression of the diffusing scent. $59 \%$ said that the scent was too weak; $30 \%$ of them affirmatively liked the scent. None of the interviewees answered that they disliked the scent. Lastly, $49 \%$ of the interviewees expressed a positive perception of the "scented ATM".
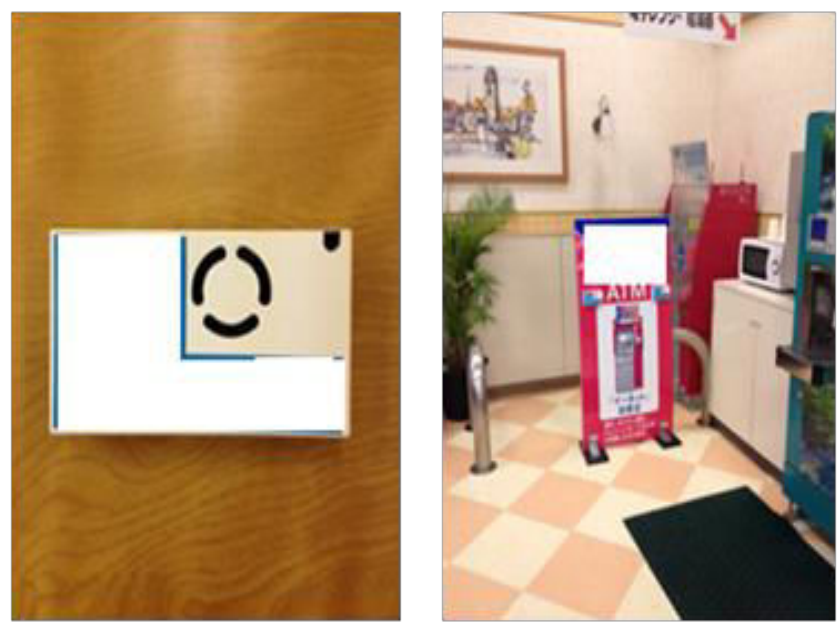

Figure 2. Pictures of the diffuser and panel. A picture was taken by the first author's assistant.

\section{CONCLUSION}

This paper provides insight into scent marketing and its implications for business. Two studies were conducted to support the usage of scent for the effective promotion of products and services that have not traditionally been associated with olfaction.

Study 1 uncovered that scent recall ratios decreased over time, as evidenced by $17 \%$ (after 6 weeks) and 6\% (after 12 weeks) of the student participants recognizing the original scent provided. Additionally, more than $60 \%$ of participants recalled some of the original olfactory information ("orange, citrus-like smell").The foregoing supports the application of scent for product recall and perception as potentially useful component of overall marketing strategy.

Study 2 found that $15 \%$ of interviewees recognized the scent used around the ATM despite significant environmental disturbances (nearby bakery, wintertime face masks). None of the interviewees felt uncomfortable toward the scent and nearly half of them supported the "scented ATM". These findings also suggest that that investment in scent marketing may potentially contribute to the effective promotion of goods and services.
Results from the two studies discussed in this paper yield several insights for better scent marketing outcomes. First, scent is a very delicate chemical and biological process that cans easily be impacted by surroundings. Feedbacks from the interviews in Study 2 were disrupted by other smells in the retail outlet. Hence, it is important to manage the spatial scope, density, and longevity of scent when applying it for promotion.

Second, we learned that scent preference is quite individualistic. Therefore, it is important to select "highest common" scent among target segments. Both the psychological and physical conditions of target consumers should be considered. During Study 1, some of student participants claimed that they had the sniffles; health status strongly affects the sensory responses of humans.

Third, in order to examine the degree to which scent can contribute to perceptions of product and brand association, it is necessary to conduct further empirical research observing users for longer terms. Study 1 lasted 12 weeks, and Study 2 was conducted over two days. With refinement of research methodologies and increased statistical power, additional studies should be conducted using different methods, contexts, and time periods. Lastly, without the understanding and permission of the business community, such periodic data cannot be collected and analyzed.

\section{REFERENCES}

Emsenhuber, B. 2009. Scent Marketing: Subliminal Advertising Messages. Proceedings of informatik 2009 Conference, Lubeck. Jerman: IM Focus Das Leben.

Hirt, R. 2009. Multisensory.de - Der Blog zum Thema Sensory-Branding. http://multisensory-de.blogspot.com/ accessed on October 14th, 2017.

Hudson, R. \& Distel, H. 2002. The individuality of odor perception. UK: Cambridge University Press.

Kumamoto, J. 2013. Kaori wo Katsuyo shita Market- ing no Genjo to Kadai (Problems and Prospects for Scent Marketing). Journal of the school of humanities and culture 43: 57-78.

Michell, D.J., Kahn, B.E. \& Knasko S.C. 1995. There's something in the air: Effects of congruent or incongruent ambient odor on consumer decision making. Journal of Consumer Research 22: 229-238.

Vlahos J. 2007. Scent and Sensibility. United States: AddisonWesley Education Publisher, Inc 